\title{
Don't Fake It, Make It! Thriving in Virtual Conferences and Meetings ${ }^{1}$
}

\author{
Lauri M. Baker, Matt P. Benge, Anissa Zagonel, Jarred Shellhouse, Cheryl R. Boyer, and Phillip \\ Stokes $^{2}$
}

\section{Introduction to the Don't Fake It, Make It! EDIS Series}

Our ways of working, meeting, and networking have become more virtual than ever before. While some have embraced this modality change, others may struggle with the loss of more traditional ways of engagement. However, the virtual conference and meeting experience does not have to be a lesser version of an in-person event. When the host of these experiences has selected the virtual option as the best viable choice for delivery and intentionally prepared both the content and participants, these experiences provide engaging opportunities with qualities that can surpass those of in-person events. This series describes the preparation needed to host a successful virtual experience, as well as steps participants can take to get the most benefit from a virtual conference or meeting. The series provides tips for each method of engagement and learning to help all involved make the most of these experiences. Engagement is defined in this series as the degree participants are interacting with the content, host, and other participants in a way that is meaningful and productive to learning and the objectives of the meeting or conference. This series will also help hosts understand the value of online conferences and meetings and demonstrate how to create engagement in an online format. For the purpose of this series, the terms virtual and online will be used interchangeably.

\section{Understanding the Difference Between a Conference and a Meeting}

Virtual meetings consist of people who are typically geographically dispersed, communicating together online for a short period of time in order to achieve a common goal (Jarvenpaa et al., 1999; Frisch \& Greene, 2020; Kristof et al., 1995). Collaborators in virtual meetings can live across town or in different countries but come together using the internet to complete a task or plan future work (Frisch \& Greene, 2020; Zakaria \& Yusof, 2018). The average virtual meeting typically lasts one to two hours, has a small contingent of individuals, and has a few objectives or goals. Virtual conferences, by contrast, are typically a full day or multiple days long, comprised of many individuals, and can have numerous objectives and goals depending on the type of conference. The differences between a virtual conference and a virtual meeting are demonstrated visually in Figure 1.

1. This document is AEC702, one of a series of the Department of Agricultural Education and Communication, UF/IFAS Extension. Original publication date August 2020. Visit the EDIS website at https://edis.ifas.ufl.edu for the currently supported version of this publication.

2. Lauri M. Baker, associate professor; Matt P Benge, assistant professor, Department of Agricultural Education and Communciation; Anissa Zagonel, research and marketing associate, Center for Rural Enterprise Engagement; Jarred Shellhouse, marketing specialist, Department of Agricultural Education and Communication, UF/IFAS Extension; Cheryl R Boyer, associate professor, Department of Horticulture \& Natural Resources, Kansas State University; and Phillip Stokes, learning and organizational development specialist, Center for Public Issues Education in Agriculture and Natural Resources; UF/IFAS Extension, Gainesville, FL 32611.

The Institute of Food and Agricultural Sciences (IFAS) is an Equal Opportunity Institution authorized to provide research, educational information and other services

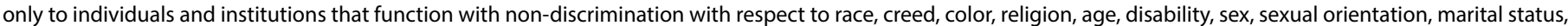

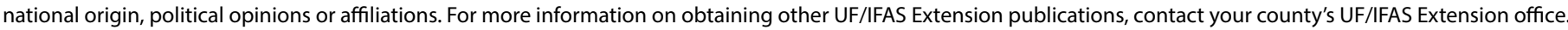
U.S. Department of Agriculture, UF/IFAS Extension Service, University of Florida, IFAS, Florida A \& M University Cooperative Extension Program, and Boards of County Commissioners Cooperating. Nick T. Place, dean for UF/IFAS Extension. 

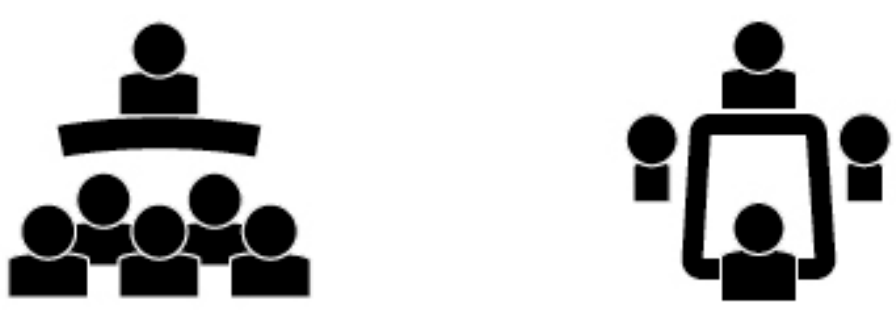

Figure 1. Illustrated differences between in-person conferences (left) and meetings (right).

\section{Deciding Between Synchronous Modes of Delivery}

Virtual conferences and meetings discussed in this series are synchronous, meaning occurring in real time. Synchronous online conferences and meetings typically happen in one of three formats: virtual, hybrid, or fusion. Understanding the benefits of each mode will ensure the virtual conference or meeting host uses the appropriate delivery method for the event. Figure 2 illustrates the differences in the three online conference and meeting types.
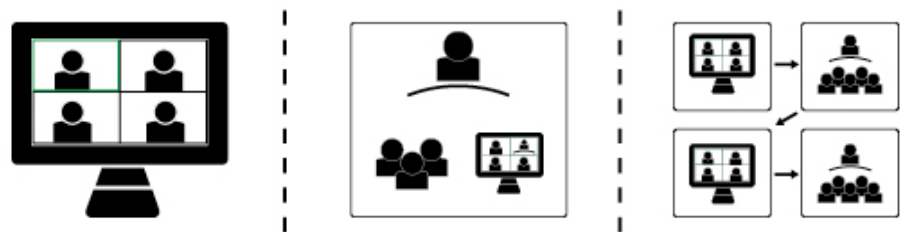

Figure 2. Illustrated variations of online conference and meeting formats: virtual (left), hybrid (middle), and fusion (right).

References to learning styles are made in the following descriptions of meeting and conference types. Details on learning styles are included in the Applying Learning Theory to Virtual Conference Spaces document (forthcoming) in this EDIS series.

Virtual: All participants attend the event entirely online at the same time (synchronously).

- Pre-event Communication: Only one message is used and tailored to one audience group.

- Content: Content is planned for online audiences only, with one engagement plan.

- Building Community: Building community refers to the engagement and dialogue between learners and participants; hosts should incorporate activities and best practices to foster community among virtual participants.

- Event Communication: Only one message tailored to one audience group is used for event communication.

- Space: Only virtual space is needed in this format.

- Learning Style: Participants have only one learning style to choose from.
- Engagement Level: Lower engagement may occur in this format due to the online structure; future articles in this series will focus on how to increase engagement in this format.

- Technology: Videoconferencing software and at least one streaming device are needed.

- Recommended Personnel: The presenter and one information technology (IT) person are recommended to support this type. The IT support can be off site.

- Logistics: Aspects to consider are the preparedness of presenters and attendees to use the streaming software and timing of presentations.

Hybrid: Everyone attends at the same time, but some are in person while others are online.

- Pre-event Communication: Two audience groups with two different messages need to be considered for preevent communication.

- Content: Two types of content should be planned, one for online audiences and one for in-person. Two separate engagement plans will be simultaneously executed.

- Building Community: Hosts should connect online and in-person participants to each other.

- Event Communication: Messages need to be tailored to two audience groups: online and in-person.

- Space: In-person meeting rooms and virtual spaces are both needed for a full conference.

- Learning Style: Participants can choose the conference style that best fits their learning style, virtual or in-person.

- Engagement Level: Online participants may have lower engagement than in-person participants.

- Technology: Hosts will simultaneously need presenter hardware (projector, monitor), a streaming device, and videoconferencing software.

- Recommended Personnel: The presenter, a team of content experts (for online participant questions), and a team of IT (on site) are recommended for online participant questions.

- Logistics: Aspects to consider are in-person participant and staff travel, lodging, and meals. Logistics for virtual participants are the streaming software preparedness for participants and hosts. The timing between the in-person and virtual participants is an important logistic aspect to manage for content and break needs. 
Fusion: All participants attend together, but some sessions are online and others are in person. This typically is over a long period of time (e.g., one session per month for 6 months to a year).

- Pre-event Communication: One audience group to consider with two different messages and details for preparation.

- Content: One type of content is planned with only online participants in mind to be delivered online, while a second type of content is planned for only in-person participants, delivered in one physical space. An example of this might be learning theory or ideas in an online session and then meeting in person to practice hands-on activities and apply the knowledge learned in the online session.

- Building Community: Hosts should use both online and in-person engagement strategies sequentially.

- Event Communication: One audience group and one message are needed for all participants.

- Space: An in-person meeting room is needed for part of the conference, and a virtual space for the other part.

- Learning Style: Participants participate in varied learning styles for conference duration.

- Engagement Level: Some sessions online may have lower engagement than in-person sessions.

- Technology: Hosts will sometimes need presenter hardware and other times a streaming device and videoconferencing software, depending on the order of the conference.

- Recommended Personnel: A presenter will always be needed, and off-site IT support is recommended for online sessions.

- Logistics: Aspects to consider for in-person portions are travel, lodging, and meals for hosts and participants. For the online portions, streaming software preparedness for hosts and participants should be considered. Timing will be a consideration for which portions should be in person and which should be online, and in which order these sessions should be done.

\section{Deciding the Correct Format for Your Conference or Meeting}

When making decisions about which type of virtual experience works for your conference or meeting, you must consider your audience and its needs. You could complete a full needs assessment if you have the time and resources to do so (Benge et al., 2019). If you don't have the time or resources to conduct a full needs assessment before preparing for your conference or meeting, you can begin by asking yourself a few questions or by doing a quick preconference or premeeting survey.

Below are some questions to ask yourself about your audience:

1. Does my audience own adequate technology to participate virtually, such as a webcam, computer, or microphone?

2. Has my audience expressed interest in an online experience?

3. Is it difficult, expensive, or time-consuming for participants to travel to one location to meet?

4. Will my participants enjoy the online experience?

5. Is my audience regularly completing online activities or working in online spaces?

6. Is my audience open to a new format (if audience members have previously only met in person)?

7. Is my audience currently being asked to work from home?

8. Is leaving the home or office difficult for my audience?

9. Is my audience innovative?

10. Does my audience like new experiences?

11. Has my audience been successful in previous online experiences?

Your audience's needs are of major importance, but you also have to be ready to host a virtual conference or meeting, or it will not be a good experience for you or your audience. In addition to the questions above relating to your audience and their needs, you should consider your needs as well:

12. Do I have the resources and/or knowledge to host and troubleshoot online and technological issues associated with virtual experiences?

13. Do I have a committee or team for support in hosting this virtual experience?

14. Am I comfortable working and communicating online? 
15. Do I get excited about trying new things?

If you answered "yes" to the majority of these 15 questions, then a completely online experience could be the answer.

If you answered "yes" to 7 or fewer of these questions, you may want to start with a hybrid experience and see how you and your audience feel about the virtual portion.

If you answered "yes" to 4 or fewer of these questions, you may want to begin by having an in-person experience and then work to mirror that experience for the portion of your participants who may be interested in the virtual experience at a later time. This may be particularly true if you have a long-standing expectation of your event being in a certain location, or if some of your audience is adamantly opposed to or incapable of participating in a virtual experience.

No matter which of the three types of virtual experiences you select for your audience, it is important that you give the virtual experience an opportunity to succeed. This can be done by preparing with the virtual participants' needs in mind as well as creating learning experiences that translate to different learning styles across a virtual environment. Hosts often make the mistake of thinking they can simply make a video as the whole experience for online participants, and subsequently miss out on opportunities to engage with their virtual participants in a new way. Many opportunities to interact and engage online exist, so you do not want to make the virtual conference or meeting experience something people can watch without actively participating or learning.

\section{Example Virtual Conference}

This series will use an example conference implemented by the Center for Rural Enterprise Engagement (CREE) to help explain the application of strategies and lessons learned through a hybrid conference. CREE is a transdisciplinary, multi-institutional thought center that generates and synthesizes knowledge about new-media marketing; it can be found at https://ruralengagement.org. The annual conference is a hands-on learning experience for small, rural, agriculture-based businesses to improve their use of new- and social media strategy and analytics.

While some meetings take place via voice-only phone calls, this particular series will focus on online communication as the primary method for delivery of a virtual, synchronous experience.

\section{References}

Benge, M., Harder, A., \& Warner, L. (2019). Conducting the needs assessment \#1: Introduction. AEC677. Gainesville: University of Florida Institute of Food and Agricultural Sciences. https://edis.ifas.ufl.edu/wc340

Frisch, B., \& Greene, C. (2020, March 5). What it takes to run a great virtual meeting. Harvard Business Review. Retrieved from https://hbr.org/2020/03/ what-it-takes-to-run-a-great-virtual-meeting

Jarvenpaa, S. L., \& Leidner, D. E. (1999). Communication and trust in global virtual teams. Organization Science, 10(6), 791-815. https://doi.org/10.1287/orsc.10.6.791

Kristof, A. L., Brown, K. G., Sims, Jr., H. P., \& Smith, K. A. (1995). The virtual team: A case study and inductive model. In M. M. Beyerlein, D. A. Johnson, \& S. T. Beyerlein (Eds.). Advances in Interdisciplinary Studies of Work Teams: Knowledge Work in Teams (Vol. 2, pp. 229-253). JAI Press.

Zakaria, N., \& Yusof, S. A. M. (2018). Crossing cultural boundaries using the internet: Toward building a model of swift trust formation in global virtual teams. Journal of International Management, 26(1), 1-19. https://www.doi. org/10.1016/j.intman.2018.10.004

\section{Appendix: Articles in This Series}

1. Don’t Fake It, Make It! Thriving in Virtual Conferences and Meetings

2. Applying Learning Theory to Virtual Conference Spaces

3. Am I Ready? Competencies and Skill Sets Needed for Virtual Conference Hosts

4. Technology and Tools for Virtual Hosts

5. Let's Do This Right: Best Practices for Hosting Virtual Conferences

6. Host with the Most: Best Practices for Hosting Virtual Meetings

7. Best Practices for Hosting Virtual Webinars

8. Best Practices for Hosting Virtual Events and Fairs

9. Best Practices for Attending Virtual Events 